\title{
An Environmentally Conscious PSS Recommendation Method based on Users' Vague Ratings: A Rough Multi-Criteria Approach
}

Wenyan Song and Tomohiko Sakao

The self-archived postprint version of this journal article is available at Linköping University Institutional Repository (DiVA):

http:/ / urn.kb.se/ resolve?urn=urn:nbn:se:liu:diva- 142359

N.B.: When citing this work, cite the original publication.

Song, W., Sakao, T., (2017), An Environmentally Conscious PSS Recommendation Method based on Users' Vague Ratings: A Rough Multi-Criteria Approach, J ournal of Cleaner Production.

https:// doi.org/ 10.1016/j.jclepro.2017.10.092

Original publication available at:

https://doi.org/10.1016/j.jclepro.2017.10.092

Copyright: Elsevier

http:// www.elsevier.com/

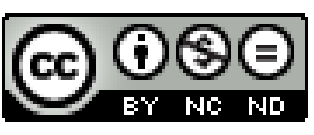




\title{
An Environmentally Conscious PSS Recommendation Method based on Users' Vague Ratings: A Rough Multi-Criteria Approach
}

\author{
Wenyan Song \\ School of Economics and Management, Beihang University, Beijing 100191, China \\ Email: songwenyan@buaa.edu.cn \\ Tomohiko Sakao \\ Division of Environmental Technology and Management, \\ Department of Management and Engineering, \\ Linköping University, 58183 Linköping, Sweden \\ Email: tomohiko.sakao@liu.se
}

\begin{abstract}
Many manufacturers are today striving to offer a large number of value-added PSSs (Product-Service Systems). The increased number of PSS hinders potential buyers from effectively discovering the most suitable PSS to satisfy their personalized requirements. To accurately find the needed or wanted PSS with lower search costs, it is effective to recommend suitable PSS solutions to the right buyers. However, service, a component of PSS, brings more subjective and imprecise information in acquiring users' preferences due to e.g. their different experience and knowledge on services. Moreover, the interactions within user's preferences are often omitted in previous methods, which may lead to inaccurate recommendation results. Therefore, to solve these problems, an innovative method for PSS recommendation is developed. This method explicitly takes into account the environmental aspect of PSSs in question so that a method user can be guided to select an environmentally superior alternative. In addition, rough DEMATEL (Decision-Making and Trial Evaluation Laboratory) is proposed to manipulate the interactions of vague user preferences in multi-criteria weight determination. Furthermore, a rough collaborative filtering approach is developed to make PSS recommendation under vague environment. A case study of elevator PSS recommendation shows the feasibility and potentials of the proposed approach. Theoretically, the new method can produce more reasonable PSS recommendation results by considering the interdependencies between different recommendation criteria. In marketing practice, the method can suggest proposals of new offerings to customers in a proactive manner.
\end{abstract}

Key words: Product-Service System, Personalization, Recommendation, Search cost, DEMATEL. 


\section{List of abbreviation}

$\begin{array}{ll}\text { AHP } & \text { Analytic Hierarchy Process } \\ \text { ANP } & \text { Analytic Network Process } \\ \text { CBF } & \text { Content based filtering } \\ \text { CF } & \text { Collaborative filtering } \\ \text { DEMATEL } & \text { Decision-Making and Trial Evaluation Laboratory } \\ \text { MCDM } & \text { Multi-criteria decision-making } \\ \text { PSS } & \text { Product-Service System } \\ \text { QFD } & \text { Quality Function Deployment }\end{array}$

\section{Introduction}

With the customer requirements diversification (Hu et al. 2011), increasing competition (Uppenberg and Strauss 2010), and environmental pressures (Umeda et al. 2012), many manufacturers are striving to offer a large number of value-adding services (Meier et al. 2010) and integrate the services with their products (Beuren et al. 2013). The services often include product support, maintenance, repair, upgrading, remanufacturing, recycling, and energy management in practice (e.g. Williams 2007, Sakao et al. 2008). This type of integrated solutions is called Product-Service System (PSS), which could decrease the lifecycle cost (Lindahl et al. 2014), increase the product life (Roy 2000) and enhance the utility delivered by a manufacturer (White et al. 1999). PSS also could help manufacturers to be differentiated from their competitors (Meier et al. 2010). It has been considered as one of the most effective instruments for enhancing resource-efficiency (Tukker 2015).

PSS providers encapsulate their PSS solutions for buyers and users to select one or more from. Over the last years, the number of PSS solutions has been increased. For instance, offered are a few times more than earlier in technology-oriented manufacturing companies (Björndal et al. 2015). Just to name a few more examples, GM introduces its On Star 1 (OS 1) service to provide many different maintenance and safety services. Apple and Nike develop new products for various customized services related to exercising by combining their products (Aggarwal et al. 2013). Thus, an information overload problem and search costs have become issues, which hinders the effective and efficient discovery of the proper PSS solutions to satisfy user's requirements. Efficiency of processing requests in purchasing services is important as reported by Hallikas et al. (2014). Worse still, the problem will be exacerbated when the buyer has incomplete understanding about his/her requirements. In order to reduce buyer's cost of seeking industrial services and enhance performance of PSS, recommending suitable services for users has become one of the most critical issues for service provider (Shen 2014). Previous retrieval approaches (e.g. keyword-based retrieval) (Rasolofo and Savoy 2003, Kara et al. 2012) are time consuming, and they often find many irrelevant results or cannot obtain highly relevant result. To facilitate users to select the PSS solutions more accurately, it is effective to proactively provide personalized recommendations for them.

Although the personalized recommendations have gained much attention in the field of Ecommerce (e.g., recommending books, CDs, movies, news articles to users) (Xiao and Benbasat 2007) based on user preferences and experiences, few previous studies have explored approaches for PSS recommendations. Many recommendation methods applied to such simple applications as examples above deal with ratings in crisp numerical scale, and they lack effective mechanism to deal with individual user preferences and ratings, which may affect the 
accuracy of the final recommendation results. Particularly, PSS is a hybrid offering of product and service, which should be described from a variety of perspectives, such as reliability, cost, and response time. Some aspects are more prominent to the user than the others and, therefore, the two criteria shouldn't be treated equally on the same rating scale. In this respect, multicriteria ratings can help improving the recommendation accuracy because it can represent more sophisticated user's preferences. However, the previous multi-criteria recommendation methods ignore the interactions between different criteria. That is, some criteria may have impacts on each other: e.g., reducing service response time may lead to increasing of the service cost. Moreover, most of the past recommendation methods are not suitable to PSS recommendation due to the features of PSS, e.g., heterogeneity (e.g. Regan 1963) and service interactions (e.g. Galvagno and Dalli 2014). These features make the users present subjective and imprecise preferences and ratings under vague environments.

Therefore, to solve the problem of PSS recommendation under vague environments, in this paper, a multi-criteria recommendation method considering PSS features is developed. Firstly, a rough DEMATEL is used to discover user preferences by manipulating the vague ratings and the interactions of recommendation criteria. Then, a rough collaborative filtering (CF) approach is developed to recommend suitable PSS solution for the target users. To our knowledge, there has been no such research in the past that proactively recommend personalized PSS considering its features. In this development, the method incorporates the environmental aspect aiming to ensure environmental consciousness for recommendation.

The rest of this paper is organized as follows. Section 2 briefly reviews the literature on PSS and personalized recommendation. Section 3 presents the proposed rough PSS recommendation method. Application of this PSS recommendation method in a case study of elevator PSSs is conducted and described in Section 4. Discussion and comparisons are also made in this section. Section 5 presents both the theoretical and practical implications. The last section concludes the present research.

\section{Literature review}

PSS has attracted academia and industry based on its economic potentials as well as expectation on its environmental superiority (Tukker 2004). As opposed to the conventional standardized after-sales service such as spare part provision, PSS offers customized service solutions to flexibly meet customer's requirements (Kindström and Kowalkowski 2009). Different users have different product using scenarios, expectations, and knowledge, and therefore PSS is supposed to be a highly customer-centered solution with added value, which is "sold" to meet user's personalized requirements. With this condition, it is effective to provide personalized recommendations to facilitate a user to accurately find the most suitable PSS solution. However, there are few previous researches on PSS recommendation.

Personalized recommendation is a method to support users' decision making by considering their preferences or constraints. Many studies have been conducted on personalized recommendation in many different fields such as news (Lee and Park 2007), movie (Ono et al. 2009), television (Baudisch and Brueckner 2005), books (Ziegler et al. 2005), music (Lee 2007), activity (Wang et al. 2010), tourism (Huang and Bian 2009), and product (Liu and Shih 2005). These recommendation approaches can be generally categorized into two types (Manouselis and Costopoulou 2007, Adomavicius and Tuzhilin 2005, Burke 2002): i.e., content based filtering (CBF) (Cantador et al. 2008) and collaborative filtering (CF) (Das et al. 
2007). Content-based recommendation methods use descriptions of the items rated to learn a relationship between the ratings of a single user and the description of the items rated. On the other hand, collaborative methods use the rating of a set of users on a set of items to make recommendations. Principally, a large number of recommendation approaches are developed for single-valued ratings. According to Adomavicius and Kwon (2007), pure CF-based recommender systems rely solely on product ratings provided by a large user community to generate personalized recommendation lists for each individual user. In traditional CF recommendation approaches, the assumption is that customers provide an overall rating for the items which they have purchased, for example, using a 5-star rating system. However, given the value of customer feedback to the business, customers in some domains are nowadays given the opportunity to provide more fine-grained feedback and to rate products and services along various dimensions (Jannach et al. 2012). To understand the relative strengths and weaknesses of smart devices (i.e., smart phones, watches and glasses), Wang (2015) proposes a marketoriented framework to accomplish product positioning and product recommendation. Naive Bayes Classifier (Rish 2001) is applied for the purpose of product recommendation in this research. To improving the effectiveness of personalized service recommendation, Zhang et al. (2013) combine social network and collaborative filtering techniques in a unified framework to predict the missing Quality of Service values of manufacturing services for an active service user.

Most previous research concentrates on product search support that enables users to locate relevant, prospective products. However, for decisions that involve trade-offs among multiple criteria, few researchers consider the identification of user purchasing criteria or delicate comparisons during the decision process, which may be more challenging than traditional product searches (Schafer et al. 1999). Liu et al. (2011) are motivated on the basic assumption that not all the criteria in a multi-criteria rating domain have the same affect in order to dominate users' decision. PSS selection usually involves a set of variables (e.g., cost, reliability, and response time) and thus can be modeled as a multi-criteria recommendation problem.

Adomavicius and Kwon (2007) introduce schemes of incorporating multi-criteria rating information in the recommendation process. The multi-criteria recommendation framework enables users to typically evaluate items from various perspectives. For example, suppose user A is interested in a PSS due to its quick service response. On the other hand, user B likes the PSS because B considers that the PSS provides higher reliability. If we were to take only the overall rating score, as in traditional single-criterion recommendation approaches, we might consider that users A and B have similar preferences. We might therefore recommend a PSS with quick service response to user B even though the PSS has lower reliability. Multi-criteria recommendations estimate the preference of users based on multi-criteria (e.g., cost, reliability, and response time) in their recommendations for items. Some researchers believe that multicriteria recommendation improves the accuracy (Tangphoklang et al. 2009, Adomavicius and Kwon 2007). Using a multi-criteria approach, Adomavicius et al. (2005) have presented a general multidimensional approach on manipulating contextual information in ranking. Zhang et al. (2009) apply Probabilistic Latent Semantic Analysis to MCDM (multi-criteria decisionmaking) recommendation using Yahoo! Movie datasets and show that it improves the performance in recommending top-k items than the single criterion. In order to model users in a multi-criteria recommendation, Lakiotaki et al. (2011) introduce recommendation framework 
which profiles users into groups, and then they employ multiple-criteria decision analysis before applying a CF algorithm. Shambour and Lu (2011) propose a hybrid multi-criteria CF approach. With the goal of improving accuracy level of multi-criteria CF methods, Jannach et al. (2012) utilize Support Vector regression to determine the importance of the individual criteria rating and leverage information derived from multi-dimensional ratings. Besides memory based studies, researchers also introduce model-based approaches for multi-criteria recommendation (Mikeli et al. 2013, Nilashi et al. 2014).

However, most of the previous researches are targeted at desktop/web recommendations of news, movie and books, etc. They do not focus on PSS environment, which requires multiple perspectives. Besides, most of the researches do not consider the interactions between different recommendation criteria even though they provide multi-criteria framework, which leads to inaccurate recommendation results. They present the key input to recommendation is information regarding the quality of the item along with the preference of the user who shared the rating. However, the previous approaches consider less about the vague and imprecise information in the ratings, and they lack uncertainty manipulation mechanisms, which will also influence the final recommendation results.

\section{The proposed method based on rough DEMATEL and rough multi-criteria CF}

\subsection{Overview of the method}

This method is intended to be used by a customer service manager and a service marketing manager when they attempt to discover buyer preferences and to proactively respond to the preferences by recommending suitable PSS solutions. The method is applicable to both industrial and consumer services. It consists of two phases. Figure 1 illustrates the overall process of the proposed method: Phase I for weight determination for recommendation criteria and Phase II for multi-criteria recommendation of PSS. To manipulate the vague ratings and the interactions of criteria, a rough DEMATEL is adopted in Phase I. Then, Phase II makes the personalized PSS recommendation based on a rough collaborative filtering approach. 

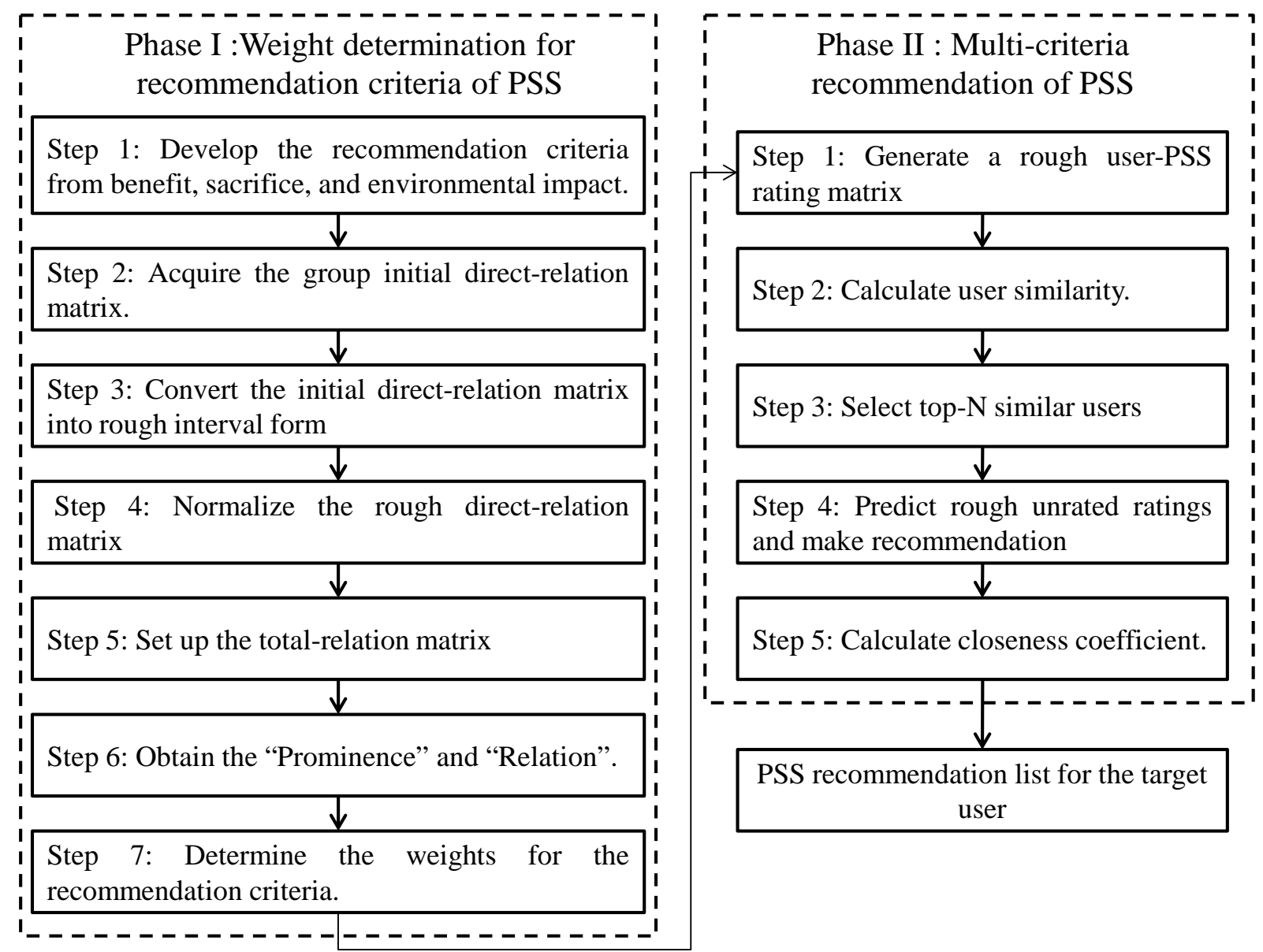

Figure 1. The framework of the proposed recommendation method for PSS.

\subsection{Phase I: Weight determination for PSS criteria with rough DEMATEL}

The determination of rough weight of PSS recommendation criteria based on the proposed rough DEMATEL method is shown in following steps.

\section{Step 1: Develop the evaluation criteria for the PSS.}

The evaluation criteria are developed according to features of the PSS in question and originate of all three categories: 1) users' benefit, 2) users' sacrifice, and 3) environmental impact. This categorization is a result of deploying a widely recognized definition of value in the industrial marketing domain by Ulaga and Chacour (2001), which is the trade-off between perceived benefits and sacrifices. In order for the method to ensure that a method user takes the environmental aspect into account, the environmental aspect is added as a mandatory category to be considered. All the criteria from the three categories are denoted as $C_{1}, C_{2}, \ldots, C_{n}$. Note that the category of a criterion does not matter mathematically and thus the category is not visible in the following mathematical formulation.

Some criteria are more prominent to the user than the others, such as the service response time may be more important than the service cost for him and therefore, the two criteria shouldn't be treated equally on the same rating scale. Moreover, some criteria may also have impacts on each other, such as reducing service response time may lead to increasing of the service cost. Thus, to achieve accurate PSS recommendation, it is necessary to know the highest predominant criteria among the others as well as the interactions between the evaluation criteria.

\section{Step 2: Acquire the group initial direct-relation matrix.}

To measure the relationship between criteria $C=\left\{C_{i} \mid i=1,2, \ldots, n\right\}$, a decision group of $p$ customers is invited to make sets of pair-wise comparisons in terms of crisp scores (Very high 
influence $=4$, High influence $=3$, Low influence $=2$, Very low influence $=1$, No influence $=0$ ) $($ Lin, 2013). Hence, $p$ crisp matrices $Z^{(1)}, Z^{(2)}, \ldots, Z^{(p)}$, each corresponding to an expert and with crisp scores as its elements, are obtained. The initial direct-relation matrix $Z^{(k)}$ of customer $k$ is denoted as:

$$
Z^{(k)}=\left[\begin{array}{cccc}
0 & Z_{12}^{(k)} & \ldots & Z_{1 n}^{(k)} \\
Z_{21}^{(k)} & 0 & \ldots & Z_{2 n}^{(k)} \\
\vdots & \vdots & \ddots & \vdots \\
Z_{n 1}^{(k)} & Z_{n 2}^{(k)} & \ldots & 0
\end{array}\right]
$$

where $Z_{i j}^{(k)}$ is the crisp score of the $k$ th customer.

Thus, the group initial direct-relation matrix $Z$ can be obtained as follows:

$$
Z=\left[\begin{array}{cccc}
\{0,0, \ldots, 0\} & \left\{z_{12}^{(1)}, z_{12}^{(2)}, \ldots, z_{12}^{(p)}\right\} & \ldots & \left\{z_{1 n}^{(1)}, z_{1 n}^{(2)}, . ., z_{1 n}^{(p)}\right\} \\
\left\{z_{21}^{(1)}, z_{21}^{(2)}, \ldots, z_{21}^{(p)}\right\} & \{0,0, \ldots, 0\} & \ldots & \left\{z_{2 n}^{(1)}, z_{2 n}^{(2)}, \ldots, z_{2 n}^{(p)}\right\} \\
\vdots & \vdots & \ddots & \vdots \\
\left\{z_{n 1}^{(1)}, z_{n 1}^{(2)}, \ldots, z_{n 1}^{(p)}\right\} & \left\{z_{n 2}^{(1)}, z_{n 2}^{(2)}, \ldots, z_{n 2}^{(p)}\right\} & \ldots & \{0,0, \ldots, 0\}
\end{array}\right]
$$

Step 3: Convert the judgments $z_{i j}^{(k)}$ in group initial direct-relation matrix $Z$ into rough form.

Assume that there is a set of $m$ classes of human judgments, $J=\left\{r_{i j}^{1}, r_{i j}^{2}, \cdots, r_{i j}^{k}, \cdots, r_{i j}^{m}\right\}$ ordered in the manner of $r_{i j}^{1}<r_{i j}^{2}<\cdots<r_{i j}^{k}<\cdots<r_{i j}^{m}$. $\mathrm{U}$ is the universe including all the objects and $Y$ is an arbitrary object of $U$, and then the lower approximation of $r_{i j}^{k}$ and the upper approximation of $r_{i j}^{k}$ can be defined as:

$$
\begin{array}{ll}
\text { Lower approximation: } & \underline{\operatorname{Apr}}\left(r_{i j}^{k}\right)=\bigcup\left\{Y \in U / J(Y) \leq r_{i j}^{k}\right\} \\
\text { Upper approximation: } & \overline{\operatorname{Apr}}\left(r_{i j}^{k}\right)=\bigcup\left\{Y \in U / J(Y) \geq r_{i j}^{k}\right\}
\end{array}
$$

Then, the judgment, $r_{i j}^{k}$, can be represented with a rough number defined by its lower limit $\underline{\operatorname{Lim}}\left(r_{i j}^{k}\right)$ and upper limit $\overline{\operatorname{Lim}}\left(r_{i j}^{k}\right)$ as follows:

$$
\begin{gathered}
\underline{\operatorname{Lim}}\left(r_{i j}^{k}\right)=\frac{\sum_{m=1}^{N_{i j L}} x_{i j}}{N_{i j L}} \\
\overline{\operatorname{Lim}}\left(r_{i j}^{k}\right)=\frac{\sum_{m=1}^{N_{i j U}} y_{i j}}{N_{i j U}}
\end{gathered}
$$

$x_{i j}$ and $y_{i j}$ are the elements of lower and upper approximation for $r_{i j}^{k} . N_{i j L}$ and $N_{i j U}$ are the number of objects included in the lower approximation and upper approximation of $r_{i j}^{k}$, respectively.

Then, all the crisp judgments $Z_{i j}^{(k)}$ in initial direct-relation matrix $Z^{(k)}$ can be converted into rough number form $R N\left(z_{i j}^{(k)}\right)$ can be obtained using equation (3)-(6), 


$$
R N\left(z_{i j}^{(k)}\right)=\left[\underline{\operatorname{Lim}}\left(z_{i j}^{(k)}\right), \overline{\operatorname{Lim}}\left(z_{i j}^{(k)}\right)\right]=\left[z_{i j}^{(k) L}, z_{i j}^{(k) U}\right]
$$

, where $Z_{i j}^{(k) L}$ and $Z_{i j}^{(k) U}$ are the lower limit and upper limit of rough number $R N\left(z_{i j}^{(k)}\right)$ in the $k$ th pair-wise comparison matrix. The interval of boundary region (i.e. $Z_{i j}^{(k) U}-Z_{i j}^{(k) L}$ ) indicates the degree of vagueness. A rough number with a smaller interval of boundary region is interpreted as more precise one.

Thus, the rough initial direct-relation matrix $\mathrm{R}\left(Z^{(k)}\right)$ for each customer can be obtained as follows:

$$
\mathrm{R}\left(Z^{(k)}\right)=\left[\begin{array}{cccc}
R N\left(z_{11}^{(k)}\right) & R N\left(z_{12}^{(k)}\right) & \ldots & R N\left(z_{1 n}^{(k)}\right) \\
R N\left(z_{21}^{(k)}\right) & R N\left(z_{22}^{(k)}\right) & \cdots & R N\left(z_{2 n}^{(k)}\right) \\
\vdots & \vdots & \ddots & \vdots \\
R N\left(z_{n 1}^{(k)}\right) & R N\left(z_{n 2}^{(k)}\right) & \cdots & R N\left(z_{n n}^{(k)}\right)
\end{array}\right]
$$

\section{Step 4: Acquire the normalized direct-relation rough matrix.}

The linear scale transformation is then used as a normalization formula to transform the criteria scales into comparable scales. The normalized direct-relation rough matrix of the $k$ th customer, denoted as $\overline{R\left(Z^{(k)}\right)}$, is given by

where

$$
\overline{\mathrm{R}\left(Z^{(k)}\right)}=\left[\begin{array}{cccc}
\overline{R N\left(z_{11}^{(k)}\right)} & \overline{R N\left(z_{12}^{(k)}\right)} & \ldots & \overline{R N\left(z_{1 n}^{(k)}\right)} \\
\overline{R N\left(z_{21}^{(k)}\right)} & \overline{R N\left(z_{22}^{(k)}\right)} & \ldots & \overline{R N\left(z_{2 n}^{(k)}\right)} \\
\vdots & \vdots & \ddots & \vdots \\
\overline{R N\left(z_{n 1}^{(k)}\right)} & \overline{R N\left(z_{n 2}^{(k)}\right)} & \ldots & \overline{R N\left(z_{n n}^{(k)}\right)}
\end{array}\right] ; \quad k=1,2, \ldots, p .
$$

Step 5: Set up the total-relation matrix $T^{(k)}$.

The total-relation matrix $T^{(k)}$ of the $\mathrm{k}^{\text {th }}$ customer can be acquired as follows based on (Lin and $\mathrm{Wu}, 2008)$ :

$$
\begin{gathered}
T^{(k)}=\left[t_{i j}^{(k) L}, t_{i j}^{(k) U}\right], \\
\left.T^{(k) s}=\left[t_{i j}^{(k) s}\right]_{n \times n}=\overline{\mathrm{R}\left(Z^{(k)}\right)}\right)^{s}\left(I-\overline{\mathrm{R}\left(Z^{(k)}\right)}\right)^{-1}, s=L, U .
\end{gathered}
$$

where $t_{i j}^{(k) L}$ and $t_{i j}^{(k) U}$ are the lower limit and upper limit of rough interval in the total-relation matrix $T^{(k)}$, and I is the unit matrix.

Step 6: Obtain the "Prominence" and "Relation".

After obtaining the total-relation matrix $T^{(k)}$, the sum of rows and the sum of columns are separately denoted as $D^{(k)}$ and $R^{(k)}$ within the total-relation matrix $T^{(k)}$ through the following formulas:

$$
D^{(k)}=\left(\left[d_{i j}^{(k) L}, d_{i j}^{(k) U}\right]\right)_{n \times 1}=\left(\left[\sum_{j=1}^{n} t_{i j}^{(k) L}, \sum_{j=1}^{n} t_{i j}^{(k) U}\right]\right)_{n \times 1}
$$




$$
R^{(k)}=\left(\left[r_{i j}^{(k) L}, r_{i j}^{(k) U}\right]\right)_{1 \times n}=\left(\left[\sum_{i=1}^{n} t_{i j}^{(k) L}, \sum_{i=1}^{n} t_{i j}^{(k) U}\right]\right)_{1 \times n}
$$

To effectively determine the "Prominence" and "Relation", it is necessary to convert the $D^{(k)}$ and $R^{(k)}$ into crisp values. The de-"roughness" of any rough number $X_{i}=\left[x_{i}^{L}, x_{i}^{U}\right]$ can be conducted as follows:

(1) Normalization

$$
\begin{gathered}
\tilde{x}_{i}^{L}=\left(x_{i}^{L}-\min _{i} x_{i}^{L}\right) / \Delta_{\min }^{\max }, \quad \tilde{x}_{i}^{U}=\left(x_{i}^{U}-\min _{i} x_{i}^{L}\right) / \Delta_{\min }^{\max } \\
\Delta_{\min }^{\max }=\max _{i} x_{i}^{U}-\min _{i} x_{i}^{L}
\end{gathered}
$$

where $\tilde{x}_{i}^{L}$ and $\tilde{x}_{i}^{U}$ are the normalized form of the $x_{i}^{L}$ and $x_{i}^{U}$, respectively.

(2) Determination of a total normalized crisp value

$$
\alpha_{i}=\frac{\tilde{x}_{i}^{L} \times\left(1-\tilde{x}_{i}^{L}\right)+\tilde{x}_{i}^{U} \times \tilde{x}_{i}^{U}}{1-\tilde{x}_{i}^{L}+\tilde{x}_{i}^{U}}
$$

(3) Computation of final crisp values $x_{i}$ for $X_{i}$

$$
x_{i}=\min _{i} x_{i}^{L}+\alpha_{i} \Delta_{\min }^{\max }
$$

We can obtain the final crisp values $d_{i}$ for $D^{(k)}$, and crisp values $r_{i}$ for $R^{(k)}$.

The vector $m_{i}$ named "Prominence" is made by adding $d_{i}$ to $r_{j}$. Similarly, the vector $n_{i}$ named "Relation" is made by subtracting $d_{i}$ to $r_{j}$.

$$
m_{i}=d_{i}+r_{j}, \quad n_{i}=d_{i}-r_{j}, \quad i=j
$$

The vector $m_{i}$ reveals how much importance the criteria have. The larger the value of $m_{i}$ the greater the overall prominence of the criterion $i$ in terms of overall relationships with other criteria. The vector $n_{i}$ divide the criteria into the cause and effect groups. When the value $n_{i}$ is positive, the criterion belongs to the cause group. Then the criterion $i$ is a cause for other criteria. If the value $n_{i}$ is negative, the criterion belongs to the effect group. Then the criterion is reliant on fulfillment of other criteria. Therefore, the causal diagram can be acquired by mapping the dataset of the $\left(m_{i}, n_{i}\right)$, providing valuable insight for making decisions.

Step 7: Determine the weights for the recommendation criteria.

The importance of the criteria $\omega_{i}^{k}$ is calculated with the following equation:

$$
\omega_{i}^{k}=\sqrt{m_{i}^{2}+n_{i}^{2}}
$$

The importance of any criterion can be normalized as follows:

$$
W_{i}^{k}=\frac{\omega_{i}^{k}}{\sum_{1 \leq i \leq n} \omega_{i}^{k}}
$$

$W_{i}^{k}$ is the rough weight of the ith criterion.

\subsection{Phase II: Multi-criteria PSS recommendation with rough CF}

The analytical procedure of the proposed rough CF (Collaborative Filtering)-based recommendation method is concisely described as follows.

Step 1: Generate a rough user-PSS rating matrix 
Each user is represented by a set of PSS-rating pairs and the summary of all those pairs can be collected into a user-PSS rating matrix in which for the $i^{\text {th }}$ user on the $j^{\text {th }}$ item under the $k^{\text {th }}$ criterion, a rating, $s_{i j k}$, is given. These ratings are described in the crisp scores (Strongly Interested=5, More Interested=4, Interested=3, Less Interested=2, Not Interested=1) according to Lu et al. (2010). There are $m$ customers in total and $n$ PSSs are provided. If user $i$ has not rated item $j$, then $r_{i j k}=$ Null. Note that more than one of the PSSs can be provided at the same time to an identical customer.

Table 1. User-PSS rating matrix

\begin{tabular}{cccccccccccccc}
\hline \multicolumn{1}{c}{ PSS1 } & \multicolumn{1}{c}{ PSS2 } & $\ldots$ & \multicolumn{4}{c}{ PSSq } \\
\hline & $C_{1}$ & $C_{2}$ & $\ldots$ & $C_{n}$ & $C_{1}$ & $C_{2}$ & $\ldots$ & $C_{n}$ & $\ldots$ & $C_{1}$ & $C_{2}$ & $\ldots$ & $C_{n}$ \\
\hline $\mathrm{U} 1$ & $S_{111}$ & $S_{112}$ & $\ldots$ & $S_{11 n}$ & $S_{121}$ & $S_{122}$ & $\ldots$ & $S_{12 n}$ & $\ldots$ & $S_{1 q 1}$ & $S_{1 q 2}$ & $\ldots$ & $S_{1 q n}$ \\
$\mathrm{U} 2$ & $S_{211}$ & $S_{212}$ & $\ldots$ & $S_{21 n}$ & $S_{221}$ & $S_{222}$ & $\ldots$ & $S_{22 n}$ & $\ldots$ & $S_{2 q 1}$ & $S_{2 q 2}$ & $\ldots$ & $S_{2 q n}$ \\
$\ldots$ & $\ldots$ & $\ldots$ & $\ldots$ & $\ldots$ & $\ldots$ & $\ldots$ & $\ldots$ & $\ldots$ & $\ldots$ & $\ldots$ & $\ldots$ & $\ldots$ & $\ldots$ \\
$\mathrm{Up}$ & $S_{p 11}$ & $S_{p 12}$ & $\ldots$ & $S_{p 1 n}$ & $S_{p 21}$ & $S_{p 22}$ & $\ldots$ & $S_{p 2 n}$ & $\ldots$ & $S_{p q 1}$ & $S_{p q 2}$ & $\ldots$ & $S_{p q n}$ \\
\hline
\end{tabular}

To transform the user-item rating matrix into rough user-item rating matrix (see Table 1), all the crisp scores $s_{i j k}$ in user-item rating matrix are converted into rough number form $R N\left(s_{i j k}\right)$ using equation (3)-(6),

$R N\left(s_{i j k}\right)=\left[s_{i j k}^{L}, s_{i j k}^{U}\right]$, where $s_{i j k}^{L}$ and $s_{i j k}^{U}$ are the lower limit and upper limit of the $R N\left(s_{i j k}\right)$,respectively.

Table 2. Rough user-item rating matrix

\begin{tabular}{llllllllll}
\hline \multicolumn{9}{c}{ PSS1 } & \multicolumn{5}{c}{ PSSq } \\
\hline & \multicolumn{1}{c}{$C_{1}$} & \multicolumn{1}{c}{$C_{2}$} & $\ldots$ & $C_{n}$ & $\ldots$ & $C_{1}$ & $C_{2}$ & $\ldots$ & $C_{n}$ \\
\hline $\mathrm{U} 1$ & $R N\left(S_{111}\right)$ & $R N\left(S_{112}\right)$ & $\ldots$ & $R N\left(S_{11 n}\right)$ & $\ldots$ & $R N\left(S_{1 q 1}\right)$ & $R N\left(S_{1 q 2}\right)$ & $\ldots$ & $R N\left(S_{1 q n}\right)$ \\
$\mathrm{U} 2$ & $R N\left(S_{211}\right)$ & $R N\left(S_{212}\right)$ & $\ldots$ & $R N\left(S_{21 n}\right)$ & $\ldots$ & $R N\left(S_{2 q 1}\right)$ & $R N\left(S_{2 q 2}\right)$ & $\ldots$ & $R N\left(S_{2 q n}\right)$ \\
$\ldots$ & $\ldots$ & $\ldots$ & $\ldots$ & $\ldots$ & $\ldots$ & $\ldots$ & $\ldots$ & $\ldots$ & $\ldots$ \\
$\mathrm{Up}$ & $R N\left(S_{p 11}\right)$ & $R N\left(S_{p 12}\right)$ & $\ldots$ & $R N\left(S_{p 1 n}\right)$ & $\ldots$ & $R N\left(S_{p q 1}\right)$ & $R N\left(S_{p q 2}\right)$ & $\ldots$ & $R N\left(S_{p q n}\right)$ \\
\hline
\end{tabular}

Normalize the rough user-item rating matrix by using the follow equations:

$$
s_{i j k}^{\prime L}=\frac{s_{i j k}^{L}}{\max _{i=1}^{p}\left\{\max \left[s_{i j k}^{L}, s_{i j k}^{U}\right]\right\}}, \quad s_{i j k}^{\prime U}=\frac{s_{i j k}^{U}}{\max _{i=1}^{p}\left\{\max \left[s_{i j k}^{L}, s_{i j k}^{U}\right]\right\}}
$$

$\left[s_{i j k}^{L}, s_{i j k}^{\prime} U\right]$ represents the lower and upper limits of normalized from of interval $\quad\left[s_{i j k}^{L}, s_{i j k}^{U}\right]$. The normalization method mentioned above is to preserve the property that the ranges of normalized interval numbers belong to $[0,1]$. Then calculate the comprehensive rough useritem rating matrix

$$
S_{i j}=\sum_{k=1}^{n} W_{i}^{k} \times R N\left(S_{i j k}\right)=\left[S_{i j}^{L}, S_{i j}^{U}\right]
$$

, where $s_{i j}^{L}$ and $s_{i j}^{U}$ are the lower limit and upper limit of the $R N\left(s_{i j k}\right)$, respectively.

Table 3. The comprehensive rough user-item rating matrix

\begin{tabular}{lllllll}
\hline & PSS1 & PSS2 & $\ldots$ & PSSk & $\ldots$ & PSSq \\
\hline $\mathrm{U} 1$ & $S_{11}$ & $S_{12}$ & $\ldots$ & $S_{1 k}$ & $\ldots$ & $S_{1 q}$ \\
$\mathrm{U} 2$ & $S_{21}$ & $S_{22}$ & $\ldots$ & $S_{2 k}$ & $\ldots$ & $S_{2 q}$ \\
$\ldots$ & $\ldots$ & $\ldots$ & $\ldots$ & $\ldots$ & $\ldots$ & $\ldots$ \\
$\mathrm{Up}$ & $S_{p 1}$ & $S_{p 2}$ & $\ldots$ & $S_{p k}$ & $\ldots$ & $S_{p q}$ \\
\hline
\end{tabular}

Step 2: Calculate user similarity. 
The similarity of users can be measured with the distance between their ratings on the same PSS.

$$
d_{\text {rating }}\left(R(U, j), R\left(U^{\prime}, j\right)\right)=\sqrt{\frac{\left(S_{i j}^{L}-S_{i j}^{L^{\prime}}\right)^{2}+\left(S_{i j}^{U}-S_{i j}^{U^{\prime}}\right)^{2}}{2}}
$$

Where $R(U, j)$ is the user U's rating on the $j$ th PSS, and $R\left(U^{\prime}, j\right)$ is the rating of user $\mathrm{U}$ on the $j$ th PSS; $d_{\text {rating }}\left(R(U, j), R\left(U^{\prime}, j\right)\right)$ denotes the distance between the rating $R(U, j)$ and $R\left(U^{\prime}, j\right)$.

Then, the distance $d_{\text {user }}\left(U, U^{\prime}\right)$ between the user $U$ and $U^{\prime}$ can be obtained as follows:

$$
d_{\text {user }}\left(U, U^{\prime}\right)=\frac{\sum_{j \in N\left(U, U^{\prime}\right)} d_{\text {rating }}\left(R(U, j), R\left(U^{\prime}, j\right)\right)}{N\left(U, U^{\prime}\right)}
$$

Where $N\left(U, U^{\prime}\right)$ is the number of PSS which the user $U$ and $U^{\prime}$ simultaneously rate. The smaller the $d_{\text {user }}\left(U, U^{\prime}\right)$ is, the larger of the similarity between the user $U$ and $U^{\prime}$.

The similarity $\operatorname{sim}\left(U, U^{\prime}\right)$ between the user $U$ and $U^{\prime}$ is calculated as follows:

$$
\operatorname{sim}\left(U, U^{\prime}\right)=\frac{1}{1+d_{\text {user }}\left(U, U^{\prime}\right)}
$$

\section{Step 3: Select top-N similar users.}

We need to select a number of neighbor users to predict ratings. In our approach, we use the top-N technique for neighbor selection (Herlocker et al. 2002). By using this method, a certain number of most similar users will be selected as neighbors. The number of neighbors is predetermined before the user neighbor selection process.

\section{Step 4: Predict rough unrated ratings and make recommendation.}

This step is to predict the ratings of every unrated PSS for target users. In this step, all the unrated ratings can be calculated and all the empty cells in the user-item rating table will be filled except the ratings to the new items which have been rated less than two times. The algorithm for prediction is as follows:

$$
P_{U, j}=\bar{R}_{U}+\frac{\sum_{V \in N} \operatorname{sim}(U, V) \times\left(R_{V, j}-\bar{R}_{V}\right)}{\sum_{V \in N} \operatorname{sim}(U, V)}=\left[P_{U, j}^{l}, P_{U, j}^{u}\right]
$$

where $P_{U, j}$ represents the final predicted ratings of user $U$ on the jth PSS. $R_{V, j}$ represents the ratings of user $\mathrm{V}$ on the jth PSS. $\mathrm{N}$ is the number of selected neighbors. $\operatorname{sim}(U, V)$ is the similarity between the user $U$ and user $V . \bar{R}_{U}$ is the average of all ratings from user $\mathrm{U}$, and $\bar{R}_{V}$ is the average of all ratings from user V. $P_{U, j}^{l}$ and $P_{U, j}^{u}$ are the lower limit and upper limit of the $P_{U, j}$.

\section{Step 5: Calculate Closeness Coefficient.}

In this final step, a closeness coefficient is computed to determine the ranking order of all PSSs' prediction values. First, the distance between each $P_{U, j}$ and value of "strongly interested (SI=5)" $\left(d_{U, j}^{+}\right)$, and the distance between each $P_{U, j}$ and value of "not interested $(N I=1) "\left(d_{U, j}^{-}\right)$can be calculated as follows: 


$$
\begin{aligned}
& d_{U, j}^{+}=\sqrt{\frac{\left(P_{U, j}^{l}-S I\right)^{2}+\left(P_{U, j}^{u}-S I\right)^{2}}{2}} \\
& d_{U, j}^{-}=\sqrt{\frac{\left(P_{U, j}^{l}-N I\right)^{2}+\left(P_{U, j}^{u}-N I\right)^{2}}{2}}
\end{aligned}
$$

A closeness coefficient is defined to determine the ranking order of all PSSs' prediction values once the $d_{U, j}^{+}$and $d_{U, j}^{-}$has been calculated. The closeness coefficient $C C_{U, j}$ is defined as:

$$
C C_{U, j}=\frac{d_{U, j}^{-}}{d_{U, j}^{-}+d_{U, j}^{+}}, j=1,2, \ldots, \mathrm{m} .
$$

There are various ways to present recommendations to the user: either by offering the best PSS, or by presenting the top-K PSSs as a recommendation list. Because we target the certainty of PSS recommendations for increasing the trust and confidence of the user towards the recommendation, it's more advisable to recommend the highly certain among the top-K most interesting PSSs. The rough predicted value $P_{U, j}$ that corresponds to $\operatorname{Min}\left(C C_{U, j}, j=1,2, \ldots\right.$, $m$ ) is the top predicted value and the top- $N$ PSSs that correspond to the top- $N$ higher raking $C C_{U, j}$ are selected as the final recommendation list for the target user.

\section{Case study}

\subsection{Background behind the case}

To validate the proposed the PSS recommendation method, it was applied to an elevator manufacturing Company M. Implementation of the proposed approach is presented step by step. Elevator Company $\mathrm{M}$ is a leading manufacturer who provides different types of elevators (e.g., passenger/freight elevator, hospital elevator, and escalator). Besides, it also provides service offerings including "Installation \& commissioning" (PSS1), "Expert advisory" (PSS2), "Life cycle data analysis" (PSS3), "Customer care" (PSS4), "Maintenance/semimonthly" (PSS5), "Emergency repair" (PSS6), "One-stop spare parts supply" (PSS7), "Operation monitoring" (PSS8), "Energy management contract" (PSS9), and "Online knowledge support" (PSS10). Considering the dynamic change of requirements over time, Company $\mathrm{M}$ decided to conduct PSS personalized recommendation. In this way, Company $\mathrm{M}$ can actively provide differentiated PSS and improve their response ability to enhance customer value and satisfaction.

\subsection{Phase I: Weight determination for elevator PSS criteria \\ Step 1: Develop the evaluation criteria for the PSS.}

All the three categories (benefit, sacrifice, and environmental impact) are considered and, as a result, six evaluation criteria are selected in this step according to the features of PSS, i.e., $C_{1}$ :Service Infrastructure (Benefit criterion), $C_{2}$ : Service Reliability (Benefit criterion), $C_{3}$ :Service Cost (Sacrifice criterion), $C_{4}$ :Service Response (Benefit criterion), $C_{5}$ :Service Competence (Benefit criterion), $C_{6}$ :Environmental Concern (Criterion of environmental impact). 


\section{Step 2: Acquire the group initial direct-relation matrix.}

In order to measure the relationships between different criteria, eight users are invited to make sets of pair-wise comparisons in terms of crisp scores of 4, 3, 2, 1, 0 . The group initial direct-relation matrix $Z$ can be obtained as follows:

$$
Z=\left[\begin{array}{cccc}
\{0,0,0,0,0,0,0,0\} & \{0,1,1,0,2,2,0,2\} & \ldots & \{2,0,1,2,1,0,1,0\} \\
\{4,2,2,4,3,1,1,4\} & \{0,0,0,0,0,0,0,0\} & & \{1,2,3,4,3,1,4,2\} \\
\{2,0,0,0,4,3,4,3\} & \{0,1,0,0,3,1,0,0\} & \ldots & \{1,2,1,2,3,2,3,3\} \\
\vdots & \vdots & \ddots & \vdots \\
\{3,2,3,1,4,2,3,2\} & \{1,2,3,1,0,2,1,0\} & \ldots & \{0,0,0,0,0,0,0,0\}
\end{array}\right]
$$

Step 3: All the crisp judgments in initial direct-relation matrix $\mathrm{Z}$ are converted into rough number form.

According to the formula (3)-(8), the rough initial direct-relation matrix $\mathrm{R}\left(Z^{(k)}\right)$ $(k=1,2, \ldots, 8)$ for each customer can be obtained. For example, when $k=1$, the first user's rough initial direct-relation matrix $\mathrm{R}\left(Z^{(1)}\right)$ is as follows:

$$
R\left(Z^{(1)}\right)=\left[\begin{array}{l}
{[0.000,0.000][0.000,1.000][2.167,3.500][0.000,0.500][0.000,1.875][0.875,2.000]} \\
{[2.625,4.000][0.000,0.000][1.500,3.000][0.714,1.167][2.875,4.000][1.000,2.500]} \\
{[0.500,3.200][0.000,0.625][0.000,0.000][0.000,1.125][0.000,1.375][1.000,2.125]} \\
{[3.375,4.000][1.286,3.500][2.000,3.400][0.000,0.000][1.500,3.000][2.333,3.333]} \\
{[2.500,3.333][1.571,3.333][1.600,2.667][0.500,1.600][0.000,0.000][2.000,2.750]} \\
{[2.286,3.250][0.600,1.667][2.500,3.333][0.429,1.250][2.000,2.625][0.000,0.000]}
\end{array}\right]
$$

\section{Step 4: Acquire the normalized rough direct-relation matrix}

To transform the criteria scales into comparable scales, the normalized direct-relation rough matrix of the $k$ th user $\overline{R\left(Z^{(k)}\right)}$ is obtained in light of the formula (9)-(11). For example, the first user's normalized direct-relation rough matrix $\mathrm{R}\left(Z^{(1)}\right)$ is obtained as follows:

$$
\overline{R\left(Z^{(1)}\right)}=\left[\begin{array}{l}
{[0.000,0.000][0.000,0.058][0.126,0.203][0.000,0.029][0.000,0.109][0.051,0.116]} \\
{[0.152,0.232][0.000,0.000][0.087,0.174][0.041,0.068][0.167,0.232][0.058,0.145]} \\
{[0.029,0.186][0.000,0.036][0.000,0.000][0.000,0.065][0.000,0.080][0.058,0.123]} \\
{[0.196,0.232][0.075,0.203][0.116,0.197][0.000,0.000][0.087,0.174][0.135,0.193]} \\
{[0.145,0.193][0.091,0.193][0.093,0.155][0.029,0.093][0.000,0.000][0.116,0.160]} \\
{[0.133,0.189][0.035,0.097][0.145,0.193][0.025,0.073][0.116,0.152][0.000,0.000]}
\end{array}\right]
$$

Step 5: Set up the total-relation matrix $T^{(k)}$.

The total-relation matrix $T^{(1)}$ of the first user can be acquired according to (12)-(13).

$$
T^{(1)}=\left[\begin{array}{l}
{[0.014,0.263][0.003,0.197][0.137,0.416][0.002,0.125][0.008,0.283][0.061,0.296]} \\
{[0.212,0.621][0.025,0.240][0.155,0.548][0.051,0.217][0.188,0.504][0.108,0.442]} \\
{[0.040,0.412][0.003,0.178][0.015,0.241][0.002,0.150][0.008,0.257][0.062,0.297]} \\
{[0.260,0.701][0.093,0.456][0.196,0.639][0.012,0.180][0.125,0.520][0.181,0.538]} \\
{[0.198,0.576][0.103,0.393][0.157,0.517][0.038,0.230][0.038,0.302][0.151,0.440]} \\
{[0.177,0.516][0.051,0.284][0.194,0.497][0.032,0.194][0.132,0.388][0.043,0.262]}
\end{array}\right]
$$


Similarly, the total-relation matrix $T^{(k)}$ of the other users can also be acquired, which are not listed here due to space limitation.

Step 6: Obtain the "Prominence" and "Relation".

The sum of rows and the sum of columns are separately denoted as $D^{(k)}$ and $R^{(k)}$ within the total-relation matrix $T^{(k)}$ through the formulas (14)-(15). $M_{i}$ and $N_{i}$ are calculated by using the formula (16)-(19). Table 4 provides the $D^{(1)}, R^{(1)}, m_{i}$ and $n_{i}$ of the user 1 (U1). Other $D^{(k)}, R^{(k)}, m_{k}$ and $n_{k}$ can be calculated in the same way.

Table 4. The $D^{(1)}, R^{(1)}, m_{i}$ and $n_{i}$ of the total-relation matrix $T^{(1)}$

\begin{tabular}{ccccccc}
\hline & C1 & C2 & C3 & C4 & C5 & C6 \\
\hline$D^{(1)}$ & {$[0.225,1.580]$} & {$[0.738,2.572]$} & {$[0.130,1.535]$} & {$[0.868,3.034]$} & {$[0.684,2.458]$} & {$[0.629,2.142]$} \\
$R^{(1)}$ & {$[0.901,1.489]$} & {$[0.277,1.489]$} & {$[0.854,1.489]$} & {$[0.136,1.489]$} & {$[0.498,1.489]$} & {$[0.606,1.489]$} \\
$m_{i}$ & 2.811 & 2.486 & 2.514 & 2.477 & 2.837 & 2.676 \\
$n_{i}$ & -1.439 & 0.88 & -1.338 & 1.74 & 0.297 & -0.04 \\
\hline
\end{tabular}

Step 7: Determine the weighs for the recommendation criteria.

The importance of the criteria $\omega_{i}^{k}$ is calculated with the equation (20)-(21). All the weighs for the criteria of different users are provided in Table 5.

Table 5. The weighs for the criteria of different users.

\begin{tabular}{ccccccc}
\hline & $\omega_{1}^{k}$ & $\omega_{2}^{k}$ & $\omega_{3}^{k}$ & $\omega_{4}^{k}$ & $\omega_{5}^{k}$ & $\omega_{6}^{k}$ \\
\hline User 1 & 0.184 & 0.153 & 0.166 & 0.176 & 0.166 & 0.156 \\
User 2 & 0.147 & 0.169 & 0.179 & 0.145 & 0.193 & 0.167 \\
User 3 & 0.175 & 0.171 & 0.159 & 0.152 & 0.163 & 0.18 \\
User 4 & 0.166 & 0.168 & 0.171 & 0.147 & 0.168 & 0.18 \\
User 5 & 0.164 & 0.156 & 0.19 & 0.148 & 0.186 & 0.156 \\
User 6 & 0.168 & 0.149 & 0.182 & 0.168 & 0.189 & 0.144 \\
User 7 & 0.169 & 0.152 & 0.182 & 0.161 & 0.17 & 0.166 \\
User 8 & 0.182 & 0.159 & 0.173 & 0.123 & 0.192 & 0.171 \\
\hline
\end{tabular}

\subsection{Phase II: Multi-criteria recommendation of elevator PSS}

Step 1: Generate a rough user-PSS rating matrix

Eight users' ratings under different criteria are collected to construct the initial user- elevator PSS rating matrix (see Table 6). User 1's ratings on "Life cycle data analysis" (PSS3), "Emergency repair" (PSS6), "Energy management contract" (PSS9), and "Online knowledge support" (PSS10) are not available. Therefore, they are represented with "Null".

Then, all the crisp ratings in the initial user-elevator PSS rating matrix are transformed into rough intervals using equation (3)-(6) to obtain the rough user- elevator PSS rating matrix (see Table 7).

By normalizing the rough user-elevator PSS rating matrix (see Table 8), the comprehensive rough user-PSS rating matrix was calculated (see Table 9) according to the equations (22)-(23). 
Table 6. User-elevator PSS rating matrix

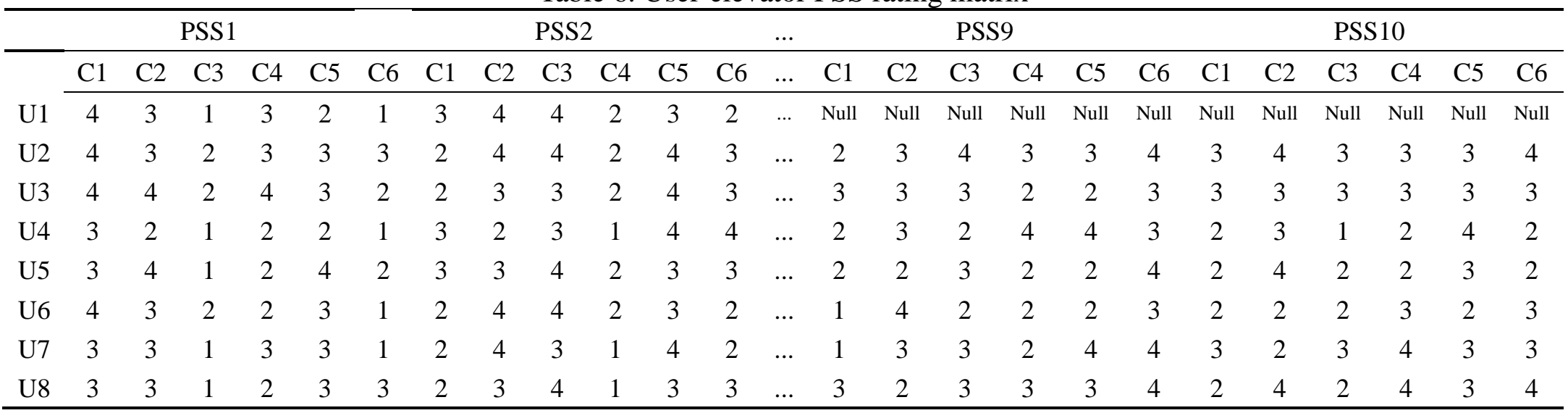

Note: Strongly Interested=5, More Interested=4,Interested=3,Less Interested=2, Not Interested=1. Null denote that no rating is available. Some ratings in the table are omitted due to the space limitations.

Table 7. The rough user-elevator PSS rating matrix

\begin{tabular}{ccccccccccccc}
\hline \multicolumn{9}{c}{ PSS1 } & \multicolumn{5}{c}{ PSS10 } \\
\hline & C1 & C2 & $\cdots$ & C5 & C6 & $\cdots$ & C1 & C2 & $\cdots$ & C5 & C6 \\
\hline U1 & {$[3.500,4.000]$} & {$[2.833,3.286]$} & $\cdots$ & {$[2.000,2.875]$} & {$[1.000,1.750]$} & $\cdots$ & Null & Null & $\cdots$ & Null & Null \\
U2 & {$[3.500,4.000]$} & {$[2.833,3.286]$} & $\cdots$ & {$[2.714,3.167]$} & {$[1.750,3.000]$} & $\cdots$ & {$[2.429,3.000]$} & {$[3.143,4.000]$} & $\cdots$ & {$[2.833,3.167]$} & {$[3.000,4.000]$} \\
U3 & {$[3.500,4.000]$} & {$[3.125,4.000]$} & $\cdots$ & {$[2.714,3.167]$} & {$[1.333,2.500]$} & $\cdots$ & {$[2.429,3.000]$} & {$[2.500,3.600]$} & $\cdots$ & {$[2.833,3.167]$} & {$[2.600,3.400]$} \\
U4 & {$[3.000,3.500]$} & {$[2.000,3.125]$} & $\cdots$ & {$[2.000,2.875]$} & {$[1.000,1.750]$} & $\cdots$ & {$[2.000,2.429]$} & {$[2.500,3.600]$} & $\cdots$ & {$[3.000,4.000]$} & {$[2.000,3.000]$} \\
U5 & {$[3.000,3.500]$} & {$[3.125,4.000]$} & $\cdots$ & {$[2.875,4.000]$} & {$[1.333,2.500]$} & $\cdots$ & {$[2.000,2.429]$} & {$[3.143,4.000]$} & $\cdots$ & {$[2.833,3.167]$} & {$[2.000,3.000]$} \\
U6 & {$[3.500,4.000]$} & {$[2.833,3.286]$} & $\cdots$ & {$[2.714,3.167]$} & {$[1.000,1.750]$} & $\cdots$ & {$[2.000,2.429]$} & {$[2.000,3.143]$} & $\cdots$ & {$[2.000,3.000]$} & {$[2.600,3.400]$} \\
U7 & {$[3.000,3.500]$} & {$[2.833,3.286]$} & $\cdots$ & {$[2.714,3.167]$} & {$[1.000,1.750]$} & $\cdots$ & {$[2.429,3.000]$} & {$[2.000,3.143]$} & $\cdots$ & {$[2.833,3.167]$} & {$[2.600,3.400]$} \\
U8 & {$[3.000,3.500]$} & {$[2.833,3.286]$} & $\cdots$ & {$[2.714,3.167]$} & {$[1.750,3.000]$} & $\cdots$ & {$[2.000,2.429]$} & {$[3.143,4.000]$} & $\cdots$ & {$[2.833,3.167]$} & {$[3.000,4.000]$} \\
\hline
\end{tabular}

Note: Some rough intervals are omitted in the table due to the space limitations. 
Table 8. The normalized rough user-elevator PSS rating matrix

\begin{tabular}{ccccccccccccc}
\hline \multicolumn{9}{c}{ PSS1 } & \multicolumn{5}{c}{ PSS10 } \\
\hline & \multicolumn{1}{c}{ C1 } & C2 & $\cdots$ & C5 & C6 & $\cdots$ & C1 & C2 & $\cdots$ & C5 & C6 \\
\cline { 2 - 11 } U1 & {$[0.875,1.000]$} & {$[0.708,0.821]$} & $\cdots$ & {$[0.500,0.719]$} & {$[0.333,0.583]$} & $\cdots$ & Null & Null & $\cdots$ & Null & Null \\
U2 & {$[0.875,1.000]$} & {$[0.708,0.821]$} & $\cdots$ & {$[0.679,0.792]$} & {$[0.583,1.000]$} & $\cdots$ & {$[0.810,1.000]$} & {$[0.786,1.000]$} & $\cdots$ & {$[0.708,0.792]$} & {$[0.750,1.000]$} \\
U3 & {$[0.875,1.000]$} & {$[0.781,1.000]$} & $\cdots$ & {$[0.679,0.792]$} & {$[0.444,0.833]$} & $\cdots$ & {$[0.810,1.000]$} & {$[0.625,0.900]$} & $\cdots$ & {$[0.708,0.792]$} & {$[0.650,0.850]$} \\
U4 & {$[0.750,0.875]$} & {$[0.500,0.781]$} & $\cdots$ & {$[0.500,0.719]$} & {$[0.333,0.583]$} & $\cdots$ & {$[0.667,0.810]$} & {$[0.625,0.900]$} & $\cdots$ & {$[0.750,1.000]$} & {$[0.500,0.750]$} \\
U5 & {$[0.750,0.875]$} & {$[0.781,1.000]$} & $\cdots$ & {$[0.719,1.000]$} & {$[0.444,0.833]$} & $\cdots$ & {$[0.667,0.810]$} & {$[0.786,1.000]$} & $\cdots$ & {$[0.708,0.792]$} & {$[0.500,0.750]$} \\
U6 & {$[0.875,1.000]$} & {$[0.708,0.821]$} & $\cdots$ & {$[0.679,0.792]$} & {$[0.333,0.583]$} & $\cdots$ & {$[0.667,0.810]$} & {$[0.500,0.786]$} & $\cdots$ & {$[0.500,0.750]$} & {$[0.650,0.850]$} \\
U7 & {$[0.750,0.875]$} & {$[0.708,0.821]$} & $\cdots$ & {$[0.679,0.792]$} & {$[0.333,0.583]$} & $\cdots$ & {$[0.810,1.000]$} & {$[0.500,0.786]$} & $\cdots$ & {$[0.708,0.792]$} & {$[0.650,0.850]$} \\
U8 & {$[0.750,0.875]$} & {$[0.708,0.821]$} & $\cdots$ & {$[0.679,0.792]$} & {$[0.583,1.000]$} & $\cdots$ & {$[0.667,0.810]$} & {$[0.786,1.000]$} & $\cdots$ & {$[0.708,0.792]$} & {$[0.750,1.000]$} \\
\hline
\end{tabular}

Note: Some rough intervals are omitted in the table due to the space limitations.

Table 9. The comprehensive rough user-PSS rating matrix

\begin{tabular}{ccccccccccc}
\hline & PSS1 & PSS2 & PSS3 & PSS4 & PSS5 & PSS6 & $\ldots$ & PSS9 & PSS10 \\
\hline U1 & {$[0.594,0.776]$} & {$[0.770,0.931]$} & null & {$[0.727,0.949]$} & {$[0.626,0.877]$} & null & $\ldots$ & null & null & \\
U2 & {$[0.688,0.902]$} & {$[0.797,0.936]$} & {$[0.690,0.862]$} & {$[0.683,0.869]$} & {$[0.581,0.823]$} & {$[0.611,0.821]$} & $\ldots$ & {$[0.668,0.889]$} & {$[0.744,0.938]$} \\
U3 & {$[0.686,0.936]$} & {$[0.735,0.894]$} & {$[0.670,0.856]$} & {$[0.588,0.871]$} & {$[0.471,0.700]$} & {$[0.669,0.862]$} & $\ldots$ & {$[0.629,0.814]$} & {$[0.701,0.899]$} \\
U4 & {$[0.512,0.716]$} & {$[0.688,0.930]$} & {$[0.638,0.823]$} & {$[0.654,0.858]$} & {$[0.564,0.785]$} & {$[0.562,0.782]$} & $\ldots$ & {$[0.636,0.865]$} & {$[0.562,0.829]$} \\
U5 & {$[0.617,0.843]$} & {$[0.769,0.929]$} & {$[0.713,0.930]$} & {$[0.699,0.913]$} & {$[0.577,0.818]$} & {$[0.586,0.805]$} & $\ldots$ & {$[0.598,0.779]$} & {$[0.627,0.822]$} \\
U6 & {$[0.638,0.816]$} & {$[0.753,0.896]$} & {$[0.694,0.852]$} & {$[0.660,0.882]$} & {$[0.529,0.766]$} & {$[0.615,0.823]$} & $\ldots$ & {$[0.540,0.763]$} & {$[0.590,0.812]$} \\
U7 & {$[0.594,0.760]$} & {$[0.690,0.866]$} & {$[0.691,0.881]$} & {$[0.620,0.831]$} & {$[0.581,0.852]$} & {$[0.688,0.903]$} & $\ldots$ & {$[0.629,0.820]$} & {$[0.700,0.907]$} \\
U8 & {$[0.627,0.812]$} & {$[0.703,0.864]$} & {$[0.645,0.822]$} & {$[0.669,0.882]$} & {$[0.579,0.869]$} & {$[0.727,0.977]$} & $\ldots$ & {$[0.656,0.875]$} & {$[0.704,0.897]$} \\
\hline
\end{tabular}

Note: Some rough intervals are omitted in the table due to the space limitations. 


\section{Step 2: Calculate user similarity.}

The user 1 doesn't provide ratings on several of the PSSs (e.g., PSS3, PSS6, PSS9 and PSS10), because the user 1 has not purchased those PSSs before. Thus, the company decided to recommend PSSs to user 1 in this case. The similarities between user 1 and the other users (see Table 10) can be calculated with the formula (24)-(26).

Table 10. The similarities between user 1 and other users

\begin{tabular}{ccccccccc}
\hline$d_{\text {rating }}\left(R\left(U_{1}, j\right), R\left(U_{k}, j\right)\right)$ & PSS1 & PSS2 & PSS4 & PSS5 & PSS7 & PSS8 & $d_{\text {user }}\left(U_{1}, U_{k}\right)$ & $\operatorname{sim}\left(U_{1}, U_{k}\right)$ \\
\hline U1-U2 & 0.111 & 0.019 & 0.065 & 0.049 & 0.094 & 0.025 & 0.061 & 0.943 \\
U1-U3 & 0.131 & 0.036 & 0.113 & 0.166 & 0.060 & 0.013 & 0.086 & 0.920 \\
U1-U4 & 0.072 & 0.058 & 0.082 & 0.078 & 0.108 & 0.033 & 0.072 & 0.933 \\
U1-U5 & 0.05 & 0.001 & 0.032 & 0.054 & 0.055 & 0.039 & 0.039 & 0.963 \\
U1-U6 & 0.042 & 0.027 & 0.067 & 0.104 & 0.091 & 0.046 & 0.063 & 0.941 \\
U1-U7 & 0.012 & 0.073 & 0.113 & 0.036 & 0.046 & 0.082 & 0.060 & 0.942 \\
U1-U8 & 0.035 & 0.067 & 0.063 & 0.034 & 0.036 & 0.029 & 0.044 & 0.958 \\
\hline
\end{tabular}

\section{Step 3: Select top- $N$ similar users.}

By using this method of top-N technique, 3 of most similar users are selected as neighbors to predict ratings. They are U5 $\left(\operatorname{sim}\left(U_{1}, U_{5}\right)=0.963\right), \mathrm{U} 8\left(\operatorname{sim}\left(U_{1}, U_{8}\right)=0.958\right)$ and U2 $\left(\operatorname{sim}\left(U_{1}, U_{2}\right)=0.943\right)$.

\section{Step 4: Predict unrated rough ratings and make recommendation.}

All the unrated ratings $P_{U, j}(j=3,6,9,10)$ are calculated with the formula (27). The ratings of PSS3, PSS6, PSS9, and PSS10 are provided in the Table 11.

Table 11 . The average of all ratings and the predicted ratings of user $\mathrm{U}_{1}$.

\begin{tabular}{ccc}
\hline & $\bar{R}_{U_{1}}$ & {$[0.662,0.870]$} \\
& $\bar{R}_{U_{5}}$ & {$[0.643,0.850]$} \\
The average of all ratings from user 1 and its similar users & $\bar{R}_{U_{8}}$ & {$[0.660,0.875]$} \\
& $\bar{R}_{U_{2}}$ & {$[0.648,0.854]$} \\
& $P_{U, 3}$ & {$[0.694,0.888]$} \\
The predicted ratings of user $U_{1}$ & $P_{U, 6}$ & {$[0.678,0.905]$} \\
& $P_{U, 9}$ & {$[0.639,0.834]$} \\
\hline
\end{tabular}

\section{Step 5: Calculating Closeness Coefficient.}

According to the formula (28)-(30), the closeness coefficients of PSS3, PSS6, PSS9, and PSS10 are computed to determine the ranking order of their prediction values. Table 12 presents the distance between each $P_{U, j}$ and value of "strongly interested $(S I=5)$ " $\left(d_{U, j}^{+}\right)$, the distance between each $P_{U, j}$ and value of "not interested $(N I=1) "\left(d_{U, j}^{-}\right)$, and the closeness coefficients. 
Table 12. $d_{U, j}^{+}, d_{U, j}^{-}$and the closeness coefficients.

\begin{tabular}{cccc}
\hline & $d_{U, j}^{+}$ & $d_{U, j}^{-}$ & ${ }^{C} C_{U, j}$ \\
\hline PSS3 & 4.210 & 0.230 & 0.052 \\
PSS6 & 4.210 & 0.237 & 0.053 \\
PSS9 & 4.264 & 0.281 & 0.062 \\
PSS10 & 4.215 & 0.235 & 0.053 \\
\hline
\end{tabular}

According to the Table 12, PSS3 is selected as the highly recommended item, because the rough predicted value of "Life cycle data analysis "(PSS3) has the smallest closeness coefficients (0.052). In this case study, PSSs corresponding to the smaller $C C_{U, j}$ are selected as the final recommendation list for the target user 1 (U1), i.e., the final recommendation list is \{PSS3 "Life cycle data analysis" (highly recommended), PSS6 "Emergency repair" and PSS10 "Online knowledge support" (fairly recommended)\}.

\subsection{Comparisons and discussion}

To validate the effectiveness and strengths of the proposed approach, the fuzzy recommendation approach based on symmetrical triangular fuzzy number has also been applied to solve the same problem. The comparative results of the proposed and fuzzy recommendation approach are shown in Figure 2.

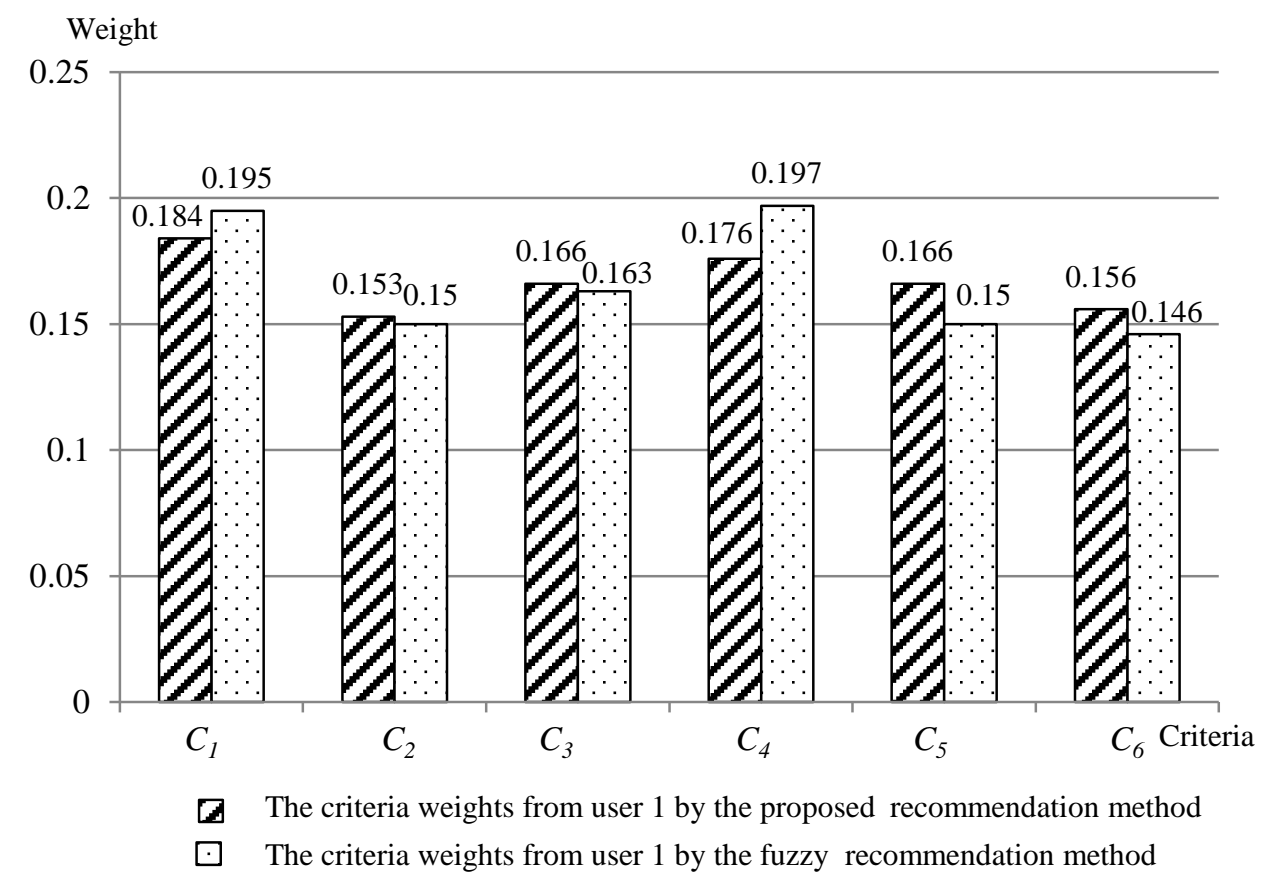

Figure 2. Comparisons between the proposed rough approach and the fuzzy approach.

The two methods produce different criteria weights for user 1 (see Figure 2). As can be seen in Figure 2, the most dominant criterion for user 1 is Service Infrastructure $\left(C_{1}\right)$ by the proposed method, while that by the fuzzy method is Service Response $\left(C_{4}\right)$. The reason is calculation by the proposed method is more precise.

Beside recommendation, the designers can also know which aspect of PSS should be improved according to the different criteria weights. For instance, it is better for designers to increase tangibility of the PSS9 with proper service infrastructure and enhance the response 
speed when recommending it to user 1 , because user 1 pays more attention to the criterion of Service Infrastructure $\left(C_{1}\right)$ and Service Response $\left(C_{4}\right)$.

Moreover, the causal diagram by the proposed method is different from that by the fuzzy method. For example, from the perspective of user 7 , the recommendation criteria Service Infrastructure $\left(C_{1}\right)$, Service Cost $\left(C_{3}\right)$, and Service Competence $\left(C_{5}\right)$, Environmental Concern $\left(C_{6}\right)$ are all considered as the effect criteria which receive influences from other criteria by the proposed method, because the "Relation" $n_{1}, n_{3}, n_{5}$ and $n_{6}$ are all negative (see Figure 3-a). However, in the fuzzy recommendation method, both Service Cost $\left(C_{3}\right)$ and Environmental Concern $\left(C_{6}\right)$ are considered as the cause criteria which may dispatch influence on other criteria, because both the "Relation" $n_{3}$ and $n_{6}$ are all positive (see Figure 3-b). This information can provide valuable suggestions for the future improvement of PSS.

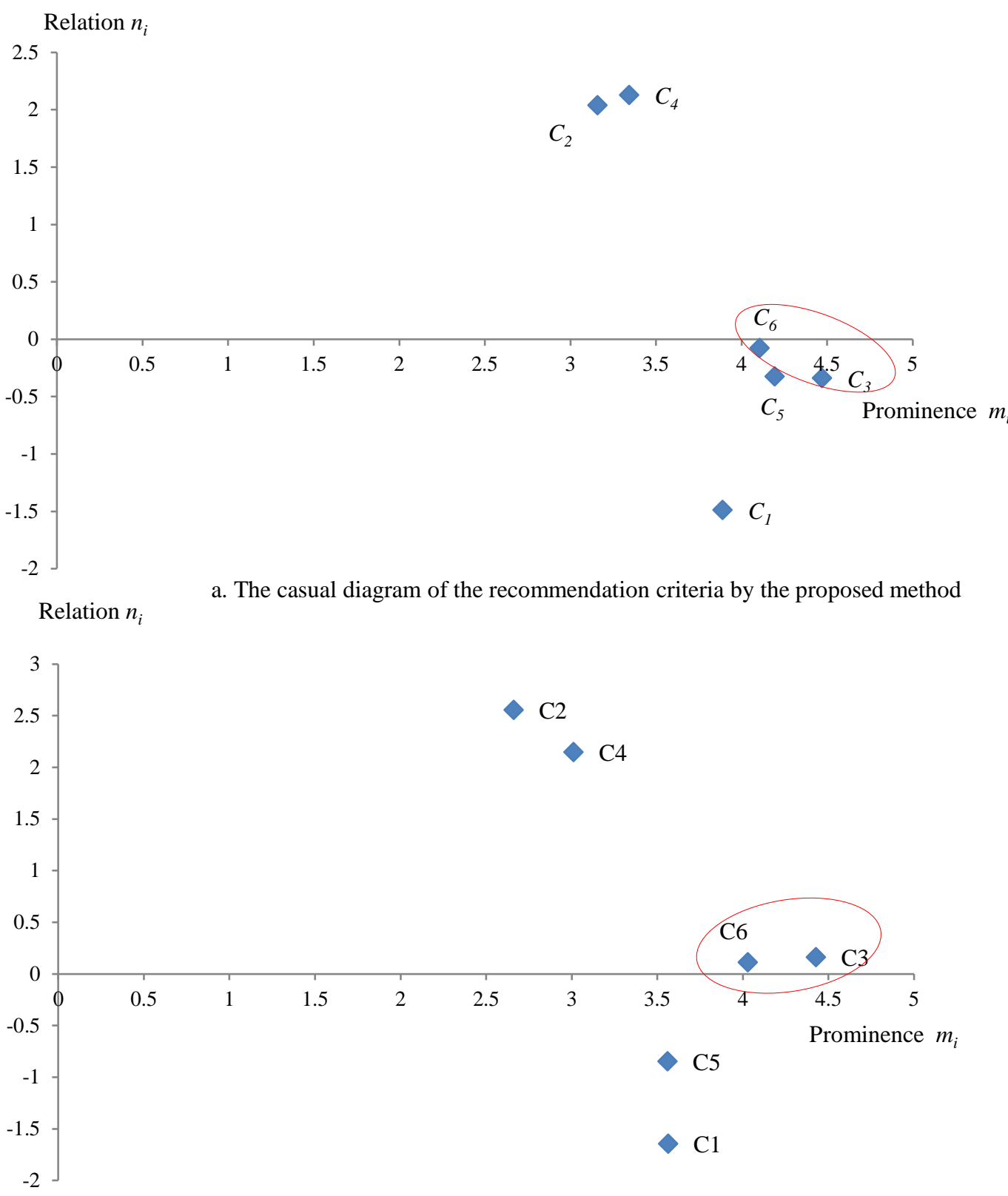

b. The casual diagram of the recommendation criteria by fuzzy method

Figure 3. The causal diagrams of user 7 by the two different methods.

Figure 4 shows the different closeness coefficients to U1 by the proposed method and those 
by the fuzzy recommendation method. PSS3 "Life cycle data analysis" is selected to be highly recommended solution for $\mathrm{U} 1$ in both the proposed method and the fuzzy recommendation method, because the $C_{3}$ is the smallest in both methods. In the proposed method, both PSS6 "Emergency repair" and PSS10 "Online knowledge support" are considered as fairly recommended, because both $C C_{6}$ and $C C_{10}$ are the second smallest among different closeness coefficients $\left(C C_{6}=C C_{10}=0.053\right)$. However, in the fuzzy recommendation method, only PSS6 "Emergency repair" is considered as fairly recommended, because $C_{6}$ is the second smallest closeness coefficient $\left(\mathrm{CC}_{6}=0.053\right)$. This is because the proposed rough recommending method flexibly considers the vagueness and rating distribution in the whole recommending process.

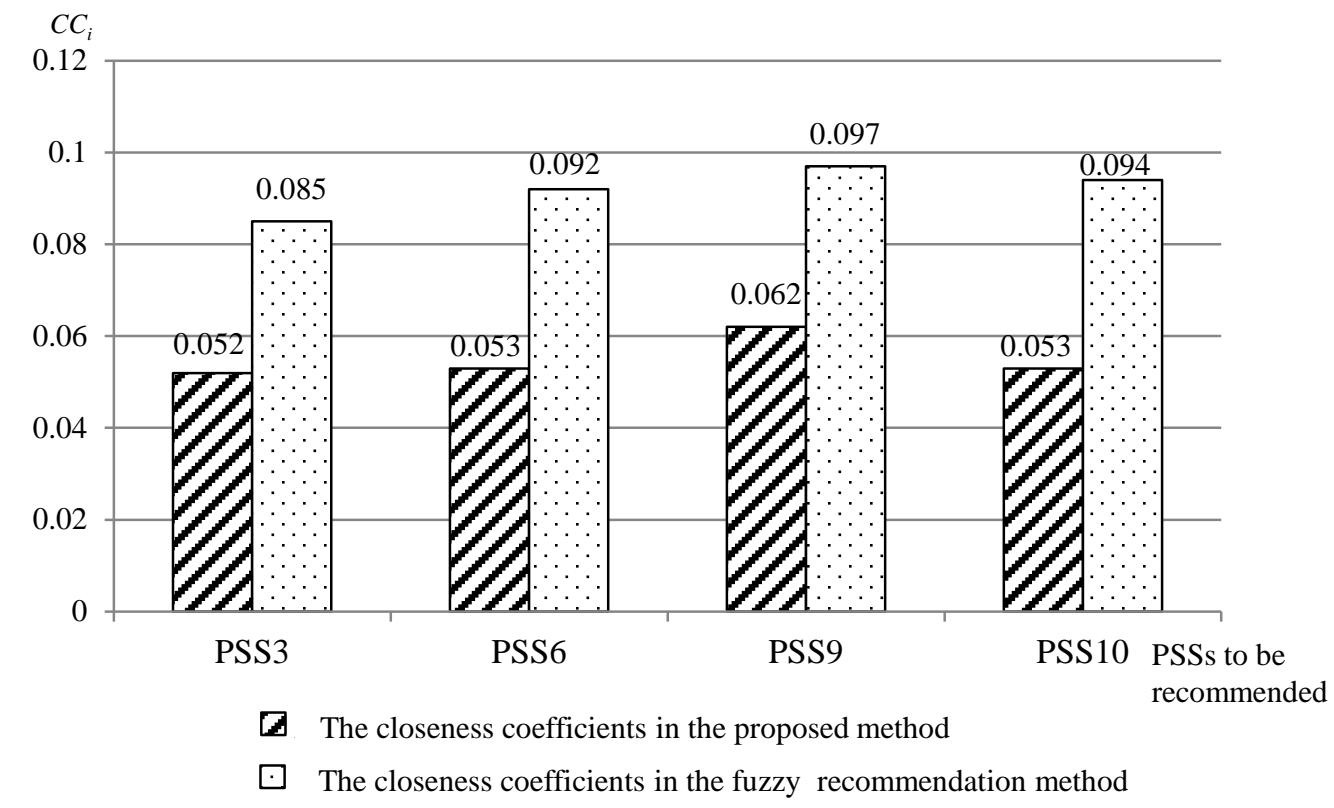

Figure 4. The closeness coefficients by the proposed method and the fuzzy recommendation method.

The differences between the proposed method and the fuzzy recommendation approach are mainly caused by their different rating manipulating mechanism. The proposed method considers not only the individual user ratings but also the rating distribution among all the users' ratings under the same criteria. For example, when rating PSS1 (Installation \& commissioning) under the criterion $C_{4}$ (Service Response), eight users provide their scores as $\{3,3,4,2,2,2,3,2\}$. The rough approach converts their scores into $\{[2.429,3.250],[2.429,3.250]$, [2.625,4.000], [2.000,2.625], [2.000,2.625], [2.000,2.625], [2.429,3.250], [2.000,2.625]\}, which considers the vagueness in group decision making process with flexible intervals. On the contrary, the fuzzy recommendation method converts their scores into $\{[2,4],[2,4],[3,5]$, $[1,3],[1,3],[1,3],[2,4],[1,3]\}$, and these interval numbers all have fixed interval of 2 . The fuzzy method uses the fixed interval of 2 to represent vagueness in different user rating. This is not real in practice, because different users have different experience and knowledge which causes different vagueness and subjectivity in their ratings. When the original scores $\{3,3,4,2,2,2,3,2\}$ change into $\{2,2,4,3,3,3,4,3\}$, the rough approach converts this judgment set into $\{[2.000,3.000]$, [2.000,3.000], [3.000,4.000], [2.667,3.333], [2.667,3.333], [2.667,3.333], [3.000,4.000], [2.667,3.333]\}, which reflects the changes of vagueness in ratings using the flexible intervals. However, the fuzzy recommendation method converts new judgment set into 
$\{[1,3],[1,3],[3,5],[2,4],[2,4],[2,4],[3,5],[2,4]\}$ which are still with fixed interval of 2 . Thus, the fuzzy conversion does not reflect rating changes in vagueness. This is mainly caused by the pre-set fuzzy membership function in the fuzzy recommendation method. Therefore, the proposed method is more flexible and close to the reality than the fuzzy recommendation method.

Although the well-known AHP/ANP (Saaty 1988, Saaty 1996)-based approaches are good MCDM (multi-criteria decision-making) approaches, they cannot be directly applied into the personalized recommendation of PSS. This is because the AHP/ANP approaches lack appropriate mechanism for addressing similarity calculation (e.g. user similarity) which is critical to the success of personalized recommendation. On the contrary, the proposed method not only has the mechanism of criterion weight determination, but also has the mechanism of user similarity calculation for PSS recommendation. Thus, the proposed method can be used to achieve personalized recommendation of PSS.

\section{Theoretical and practical implications}

From the theoretical perspective, this study develops a rough multi-criteria recommendation method for PSSs. This research fills the gap of PSS recommendation identified by a comprehensive review (Song 2017). In this way, manufactures can actively provide differentiated PSSs (Song and Sakao 2017), and thus achieve proactive response to dynamic change of requirements. This helps to differentiate the company's offerings from those by competitors. Besides, the proposed recommendation method can also identify the interdependencies between different PSS recommendation criteria, which has not been addressed in the literature on PSS. Many managers pay less attention to the interrelationships of recommendation criteria. The proposed method will help them to understand the mechanism of interdependencies between recommendation criteria. With such a decision-making tool, PSS design and marketing can achieve proactive strategy (Frambach et al. 1997) because it can support improving the PSS features in advance by discovering how recommendation criteria influence each other. Finally, the proposed method can effectively and flexibly deal with vague and imprecise information in decision making of PSS recommendation with less a priori information. In this respect, it provides a methodological contribution to the PSS literature.

The environmental aspect is embedded in this method by implementing it as one category out of the three for the criteria at the beginning (Step 1 of Phase I). This ensures to support environmental conscious recommendation. This way of implementation is the same as other existing environmental conscious methods such as (Lin and Tseng 2016). Further, it should be noted that, in proposing a new method, the authors directly took an opportunity to take the environmental aspect into account. This is new compared with most traditional ways of method development, where first a method that does not explicitly consider the environmental aspect is developed and later it is extended to an environmentally conscious one: e.g. Green Quality Function Deployment (QFD) (Cristofari et al. 1996) developed after QFD (Akao 1990) as reviewed by Fargnoli and Sakao (2016). This contributes to much needed faster development of knowledge in the sustainability discipline.

To sum up, the proposed method reveals the following features: first, different with the single rating-based recommendation method, this research proposes a rough multi-criteria approach of personalized PSS recommendation, which reduces the users' burden on time-consuming and error-prone manual PSS selection, and helps PSS providers proactively to respond to user's 
personal preferences. Second, the proposed method successfully extends the DEMATEL method by applying rough aggregation approach, and it can well manipulate the problem of recommendation criteria evaluation in vague environment. Hence, it can effectively deal with vague and imprecise information. Third, the rough DEMATEL-based weighting method considers the interactions between different criteria. Thus, the complexity of PSS features is easier to be captured and more profound information can be provided for the PSS recommendation. Fourth, the proposed recommendation method considers not only the user's subjective rating on PSS but also the objective distribution of the rating by using the rough number, and it deals with ratings in rough scale to accurately capture user preferences and ratings for the reasonable recommendation results. Last but not least, the method has implemented consideration of the environmental aspect, and effectively supports a user to take into account the environmental aspect in his/her choice.

Beside the theoretical implications, the proposed method provides several practical benefits. First, the time and efforts needed to get data for the method in practice from a provider and a customer can be marginal. This is positive for dissemination of the method into industry. Second, the method can be used as a standardized procedure at a company, avoiding discussion based on subjective or biased opinions of different users of the method. This contributes to efficient decision making at a company. Furthermore, the method can reduce risk of human errors especially in case the method is implemented as computer software. Third, the method can guide inexperienced staffs in decision making, avoiding risk of inappropriate decision making due to lack of knowledge. Fourth, the method can suggest proposals of new offerings that may not be found with ease and, based on them, the company can make proposals to customers in a proactive manner. This has potential to increase customers' loyalty to the provider and the provider's sales. Fifth, the method has a wide range of application areas, both from business to business and from business to consumers. Last but not least, a user of this method is forced to consider the environmental aspect because of the environmental category embedded in the method. This is practically effective, because a user in practice has a risk to overlook the environmental aspect. This is a relevant issue because nowadays a diversity of customer preferences need to be handled and at the same time the environmental aspect should not be forgotten (Sakao and Fargnoli 2010). A comprehensive list for the environmental criteria, as presented in e.g. (Khoshnava et al. 2016), would make the method stronger from the practical viewpoint, however it is a matter of contents and thus beyond the paper's scope.

\section{Conclusion}

This paper develops a new, environmentally conscious multi-criteria recommendation method for Product-Service System (PSS) based on rough set theory. The presented approach makes use of the rough DEMATEL to manipulate the interactions of vague user preferences in weight determination for criteria. Besides, it utilizes a rough collaborative filtering (CF) approach to make PSS recommendation for the target users under subjective and vague environment. The validation of the proposed method in elevator PSS recommendation shows that it can be used as an effective decision support tool for PSS selection among others. Theoretically, the proposed method can recommend more suitable PSS by considering the interrelationships between recommendation criteria. Besides, the method can also proactively suggest proposals of new offerings to customers in marketing practice, which may potentially increase the PSS provider's sales and customers' loyalty to the provider. 
The paper pioneered a new promising topic of recommendation methods for PSSs. Although the specific proposed method has strengths, it also has a drawback, i.e., users often do not give ratings for all the criteria, which may cause incomplete rating data. Thus, in the future, more advanced methods that build upon this paper are expected to be developed. For instance, Bayesian models may be integrated for handling incomplete rating data. Furthermore, more validation work is necessitated to gain external validity.

\section{Acknowledgments}

The work described in this paper was supported by the National Natural Science Foundation of China (Grant No. 71501006), and the Fundamental Research Funds for the Central Universities. We want to add appreciation here also for the editor and the anonymous reviewers upon acceptance. This research work was supported also in part by the Mistra REES (Resource Efficient and Effective Solutions) program (Grant No. 2014/16) funded by Mistra (The Swedish Foundation for Strategic Environmental Research). The authors wish to express their deep appreciation to the case company for its support.

\section{Dataset}

Upon acceptance of the manuscript, the data set used in Section 4 will be available at an appropriate space such as the first author's ResearchGate page.

\section{References}

Adomavicius, G., \& Tuzhilin, A. (2005). Toward the next generation of recommender systems: A survey of the state-of-the-art and possible extensions. Knowledge and Data Engineering, IEEE Transactions on, 17(6), 734-749.

Adomavicius, G., Sankaranarayanan, R., Sen, S., \& Tuzhilin, A. (2005). Incorporating contextual information in recommender systems using a multidimensional approach. ACM Transactions on Information Systems (TOIS), 23(1), 103-145.

Adomavicius, G., \& Kwon, Y. (2007). New recommendation techniques for multicriteria rating systems. Intelligent Systems, IEEE, 22(3), 48-55.

Aggarwal, A., Chan, F. T., \& Tiwari, M. K. (2013). Development of a module based service family design for mass customization of airline sector using the coalition game. Computers \& Industrial Engineering, 66(4), 827-833. .

Akao, Y. (1990). Quality Function Deployment, Portland, OR: Productivity Press.

Baudisch, P., \& Brueckner, L. (2005). TV scout: lowering the entry barrier to personalized TV program recommendation. In From Integrated Publication and Information Systems to Information and Knowledge Environments (pp. 299-309). Springer Berlin Heidelberg.

Beuren, F. H., Ferreira, M. G. G., \& Miguel, P. A. C. (2013). Product-service systems: a literature review on integrated products and services. Journal of Cleaner Production, 47, 222-231.

Björndal, P., Eriksson, E., \& Artman, H. (2015). From Transactions to Relationships: Making Sense of User-Centered Perspectives in Large Technology-Intensive Companies. In Human Work Interaction Design. Work Analysis and Interaction Design Methods for Pervasive and Smart Workplaces (pp. 114-124). Springer, Cham.

Burke, R. (2002). Hybrid recommender systems: Survey and experiments. User modeling and user-adapted interaction, 12(4), 331-370. 
Cantador, I., Bellogín, A., \& Castells, P. (2008, December). Ontology-based personalised and context-aware recommendations of news items. In Proceedings of the 2008 IEEE/WIC/ACM International Conference on Web Intelligence and Intelligent Agent Technology-Volume 01 (pp. 562-565). IEEE Computer Society.

Das, A. S., Datar, M., Garg, A., \& Rajaram, S. (2007, May). Google news personalization: scalable online collaborative filtering. In Proceedings of the 16th international conference on World Wide Web (pp. 271-280). ACM.

Cristofari, M., Deshmukh, A., \& Wang, B. (1996). Green Quality Function Deployment. International Journal of Environmentally Conscious Design \& Manufacturing, 5(2), 13-18.

Fargnoli, M. \& Sakao, T. (2016). Uncovering differences and similarities among Quality Function Deployment based methods in Design for X - benchmarking in different domains. Quality Engineering, doi: 10.1080/08982112.2016.1253849, 1-23.

Frambach, R. T., Wels-Lips, I., \& Gündlach, A. (1997). Proactive product service strategies: an application in the European health market. Industrial Marketing Management, 26(4), 341352.

Galvagno, M. \& Dalli, D. (2014). Theory of value co-creation: a systematic literature review. Managing Service Quality, 24(6), 643-683.

Hallikas, J., Immonen, M., Pynnönen, M., \& Mikkonen, K. (2014). Service purchasing and value creation: Towards systemic purchases. International Journal of Production Economics, 147, 53-61.

Herlocker, J., Konstan, J. A., \& Riedl, J. (2002). An empirical analysis of design choices in neighborhood-based collaborative filtering algorithms. Information retrieval, 5(4), 287-310.

Hu, S. J., Ko, J., Weyand, L., ElMaraghy, H. A., Lien, T. K., Koren, Y., Bley, H., Chryssolouris, G., Nasr, N., \& Shpitalni, M. (2011). Assembly system design and operations for product variety.CIRP Annals-Manufacturing Technology, 60(2), 715-733.

Huang, Y., \& Bian, L. (2009). A Bayesian network and analytic hierarchy process based personalized recommendations for tourist attractions over the Internet. Expert Systems with Applications, 36(1), 933-943.

Jannach, D., Karakaya, Z., \& Gedikli, F. (2012, June). Accuracy improvements for multicriteria recommender systems. In Proceedings of the 13th ACM Conference on Electronic Commerce (pp. 674-689). ACM.

Kara, S., Alan, Ö., Sabuncu, O., Akpınar, S., Cicekli, N. K., \& Alpaslan, F. N. (2012). An ontology-based retrieval system using semantic indexing. Information Systems, 37(4), 294305.

Kindström, D., \& Kowalkowski, C. (2009). Development of industrial service offerings: a process framework. Journal of service Management, 20(2), 156-172.

Khoshnava, S. M., Rostami, R., Valipour, A., Ismail, M., \& Rahmat, A. R. (2016). Rank of green building material criteria based on the three pillars of sustainability using the hybrid multi criteria decision making method. Journal of Cleaner Production, in press, doi 10.1016/j.jclepro.2016.10.066.

Lakiotaki, K., Matsatsinis, N. F., \& Tsoukias, A. (2011). Multicriteria user modeling in recommender systems. IEEE Intelligent Systems, 26(2), 64-76.

Lee, J. S., \& Lee, J. C. (2007). Context awareness by case-based reasoning in a music recommendation system. In Ubiquitous Computing Systems (pp. 45-58). Springer Berlin 
Heidelberg.

Lee, H. J., \& Park, S. J. (2007). MONERS: A news recommender for the mobile web. Expert Systems with Applications, 32(1), 143-150.

Lin, C. J., \& Wu, W. W. (2008). A causal analytical method for group decision-making under fuzzy environment. Expert Systems with Applications, 34(1), 205-213.

Lin, R. J. (2013). Using fuzzy DEMATEL to evaluate the green supply chain management practices. Journal of Cleaner Production, 40, 32-39.

Lin, Y.-H., \& Tseng, M.-L. (2016). Assessing the competitive priorities within sustainable supply chain management under uncertainty. Journal of Cleaner Production, 112, 21332144.

Lidahl, M., Sundin, E., \& Sakao, T. (2014). Environmental and Economic Benefits of Integrated Product Service Offerings Quantified with Real Business Cases, Journal of Cleaner Production, 64, 288-296.

Liu, D. R., \& Shih, Y. Y. (2005). Integrating AHP and data mining for product recommendation based on customer lifetime value. Information \& Management,42(3), 387-400.

Liu, L., Mehandjiev, N., \& Xu, D. L. (2011, October). Multi-criteria service recommendation based on user criteria preferences. In Proceedings of the fifth ACM conference on Recommender systems (pp. 77-84). ACM.

Lu, J., Shambour, Q., Xu, Y., Lin, Q., \& Zhang, G. (2010). BizSeeker: a hybrid semantic recommendation system for personalized government-to-business e-services. Internet Research, 20(3), 342-365.

Manouselis, N., \& Costopoulou, C. (2007). Experimental analysis of design choices in multiattribute utility collaborative filtering. International Journal of Pattern Recognition and Artificial Intelligence, 21(02), 311-331.

Meier, H., Roy, R., \& Seliger, G. (2010). Industrial product-service systems-IPS 2. CIRP Annals-Manufacturing Technology, 59(2), 607-627.

Manouselis, N., \& Costopoulou, C. (2007). Analysis and classification of multi-criteria recommender systems. World Wide Web, 10(4), 415-441.

Mikeli, A., Apostolou, D., \& Despotis, D. (2013, November). A multi-criteria recommendation method for interval scaled ratings. In Web Intelligence (WI) and Intelligent Agent Technologies (IAT), 2013 IEEE/WIC/ACM International Joint Conferences on (Vol. 3, pp. 9-12). IEEE.

Nilashi, M., bin Ibrahim, O., \& Ithnin, N. (2014). Multi-criteria collaborative filtering with high accuracy using higher order singular value decomposition and Neuro-Fuzzy system. Knowledge-Based Systems, 60, 82-101.

Ono, C., Kurokawa, M., Motomura, Y., \& Asoh, H. (2007). A context-aware movie preference model using a Bayesian network for recommendation and promotion. In User Modeling 2007 (pp. 247-257). Springer Berlin Heidelberg.

Rasolofo, Y., \& Savoy, J. (2003). Term proximity scoring for keyword-based retrieval systems (pp. 207-218). Springer Berlin Heidelberg.

Regan, W. J. (1963). The Service Revolution. Journal of Marketing, 47(July), 57-62.

Rish, I. (2001). An empirical study of the naive Bayes classifier. In IJCAI 2001 workshop on empirical methods in artificial intelligence (Vol. 3, No. 22, pp. 41-46). IBM.

Ronald, T. A., Charles, M. T., \& Catherine, G. (2007). Product/Service-System Development- 
An explorative case study in a manufacturing company. Guidelines for a Decision Support Method Adapted to NPD Processes.

Roy, R. (2000). Sustainable product-service systems. Futures, 32(3), 289-299.

Saaty, T. L. (1988). What is the analytic hierarchy process?. In Mathematical models for decision support (pp. 109-121). Springer, Berlin, Heidelberg.

Saaty, T. L. (1996). Decision making with dependence and feedback: The analytic network process (Vol. 4922). Pittsburgh: RWS publications.

Sakao, T., \& Fargnoli, M. (2010). Customization in Ecodesign: A Demand-side Approach Bringing New Opportunities? The Journal of Industrial Ecology, 14(4), 529 - 532.

Sakao, T., Napolitano, N., Tronci, M., Sundin, E., \& Lindahl, M. (2008). How Are ProductService Combined Offers Provided in Germany and Italy? - Analysis with Company Sizes and Countries -. Journal of Systems Science and Systems Engineering, 17(3), 367-381.

Schafer, J. B., Konstan, J., \& Riedl, J. (1999, November). Recommender systems in ecommerce. In Proceedings of the 1st ACM conference on Electronic commerce (pp. 158166). ACM.

Shambour, Q., \& Lu, J. (2011, August). A hybrid multi-criteria semantic-enhanced collaborative filtering approach for personalized recommendations. In Proceedings of the 2011 IEEE/WIC/ACM International Conferences on Web Intelligence and Intelligent Agent Technology-Volume 01 (pp. 71-78). IEEE Computer Society.

Shen, A. (2014). Recommendations as personalized marketing: insights from customer experiences. Journal of Services Marketing, 28(5), 414-427.

Song, W. (2017). Requirement management for product-service systems: Status review and future trends. Computers in Industry, 85, 11-22.

Song, W., \& Sakao, T. (2017). A customization-oriented framework for design of sustainable product/service system. Journal of Cleaner Production, 140, 1672-1685.

Tangphoklang, P., Maneeroj, S., \& Takasu, A. (2010). Advanced Representative and Dynamic User Profile based on MCDM for Multi-Criteria RS. In P. Powell (Ed.), IADIS International Conference Information Systems (pp. 53-60).

Tukker, A. (2004). Eight types of product-service system: eight ways to sustainability? Experiences from SusProNet. Business strategy and the environment, 13(4), 246-260.

Tukker, A. (2015). Product services for a resource-efficient and circular economy-a review. Journal of Cleaner Production, 97, 76-91.

Ulaga, W., \& Chacour, S. (2001). Measuring Customer Perceived Value in Business Markets. Industrial Marketing Management 30, 525-540.

Umeda, Y., Takata, S., Kimura, F., Tomiyama, T., Sutherland, J. W., Kara, S., ... \& Duflou, J. R. (2012). Toward integrated product and process life cycle planning-An environmental perspective. CIRP Annals-Manufacturing Technology, 61(2), 681-702.

Uppenberg, K.,Strauss, H.2010. Innovation and productivity growth in the EU services sector. European Investment Bank.

Wang, C. Y., Wu, Y. H., \& Chou, S. C. T. (2010). Toward a ubiquitous personalized daily-life activity recommendation service with contextual information: a services science perspective. Information Systems and E-Business Management, 8(1), 13-32.

Wang, C. H. (2015). A market-oriented approach to accomplish product positioning and product recommendation for smart phones and wearable devices. International Journal of 
Production Research, 53(8), 2542-2553.

White, A.L., Stoughton, M., Feng, L. 1999. Servicising: The quiet transition to extended product responsibility. Boston, MA: US Environmental Protection Agency, Office of Solid Waste, 97.

Williams, A. (2007). Product service systems in the automobile industry: contribution to system innovation?. Journal of Cleaner Production, 15(11), 1093-1103.

Xiao, B., \& Benbasat, I. (2007). E-commerce product recommendation agents: Use, characteristics, and impact. Mis Quarterly, 31(1), 137-209.

Zhang, Y., Zhuang, Y., Wu, J., \& Zhang, L. (2009). Applying probabilistic latent semantic analysis to multi-criteria recommender system. Ai Communications,22(2), 97-107.

Zhang, W. Y., Zhang, S., Chen, Y. G., \& Pan, X. W. (2013). Combining social network and collaborative filtering for personalised manufacturing service recommendation. International Journal of Production Research, 51(22), 6702-6719.

Ziegler, C. N., McNee, S. M., Konstan, J. A., \& Lausen, G. (2005, May). Improving recommendation lists through topic diversification. In Proceedings of the 14th international conference on World Wide Web (pp. 22-32). ACM. 